\title{
The obscure clarity of starlight
}

\section{Anselm Kiefer builds monumental souvenirs of the night sky.}

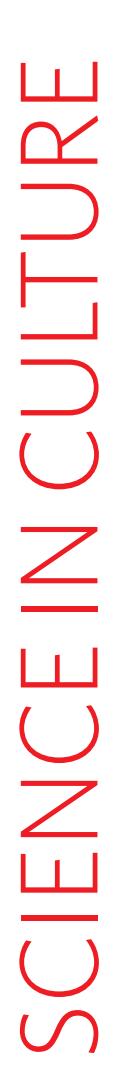

Pete Jeffs

"Your age and my age and the age of the world cannot be measured in years," wrote Austrian author Ingeborg Bachmann in her poem Das Spiel ist aus (The game is up). It is the sheer size of Anselm Kiefer's Sternenfall (Falling stars) installation in the restored Grand Palais in Paris that projects the visitor into the immeasurable.

The German artist is the first exhibitor in a new annual event called Monumenta. Each year, the Grand Palais will host a different artist to show work of monumental proportions. Kiefer's mega-installation, on view until 8 July 2007, reflects his interest in the astronomical sky.

\section{Kiefer is among the most important} contemporary artists. He gained notoriety in 1969, with his series of photographs entitled Besetzungen (Occupations), which depict the artist amongst European landscapes making the Hitlerian salute.

In 1993, he moved to the south of

France. It was perhaps the vast, starry skies of his new home in Barjac that led him to contemplate the heavens, and the cosmic reality that we ourselves are born of stardust. He frequently uses sunflower seeds; the "heliotropic spiralling seed-head is a condensed 'negative print' of the starry night sky, a cosmos full of black stars".

seven cavernous 'houses' each containing one or many canvases, such as the 2001 painting Andromeda, illustrated here. On entry, the visitor is confronted with a pile of rubble, littered with books made of lead and the glass shards of fallen stars, each numbered from a recent star map. The rubble is that of a collapsed tower entitled Dashed Hope, one of three built from hollow concrete blocks. Of the other towers, one, the title piece of the exhibition, stands 17 metres high. The third tower, rising eight metres above the spectator, is called Sun Ship, evoking a giant vessel. An array of sunflowers, a solar motif, protrudes from the top.

Shortly before his death in 1986, Joseph Beuys, Kiefer's

He has also been influenced by the ideas of Robert Fludd, the sixteenth century thinker, that each plant on Earth has a celestial equivalent, and the human body is a condensed version of the cosmos. But alongside this mysticism, Kiefer makes full use of modern astronomy.

His Monumenta exhibition comprises compatriot and fellow artist, told Keifer that through immense personal effort we can enter a domain "where cathedrals may be built". In Monumenta, Kiefer not only enters that domain, but brings back souvenirs from the starry voyage.

Pete Jeffs is an artist who lives and works in Paris.

\section{Bloggers unite}

\section{The Open Laboratory: The Best Writing on \\ Science Blogs 2006 \\ Edited by Bora Zivkovic \\ Lulu: 2007. 336 pp. \$19.85, £10.99}

\section{Paul Stevenson}

The Open Laboratory is a collection of writing from science blogs, selected and published by the energetic US biologist-blogger Bora Zivkovic with the help of the blogging community. In the run-up to the first conference of science bloggers earlier this year in North Carolina, Zivkovic took it upon himself to collate the fifty best posts put up by the end of 2006. Topics include micro black holes, bird migration, human sleep patterns, evolution, quantum mechanics and psychology. The writing ranges from $\mathrm{PhD}$ students enthusing about concepts from their research areas, to opinion pieces on themes such as the rights and wrongs of particle-physics funding, intelligent design and political interference in science policy.

This wide-ranging book provides something - hopefully many things - for everyone. Par- ticularly enjoyable is browsing entries about areas of science away from one's own research interests. As a physicist, I learned a lot about the origin of mitochondria from the representative entry of Carl Zimmer's award-winning blog The Loom. I was pleased, too, to see entries from some of the highly trafficked blogs that I habitually read and enjoy, such as The Panda's Thumb and Cocktail Party Physics.

By their nature, blogs are dynamic. A post typically bristles with links out to elsewhere on the web and accretes an ever-changing exchange of comments between readers and the author. To capture this energy and texture in a static book is a challenge that the editor fully acknowledges in his introduction. The solution Zivkovic fixes on for The Open Laboratory is to pick posts that he feels work in isolation, to list links as footnotes and to omit the comment strings.

The results of this snapshot editing process are mixed, and sometimes sloppy. For example, the freewheeling satire of the post, "Hurray for being eaten by a bear!", from the blog Thoughts From Kansas is hard to appreciate out of con- text. Plus, the URLs supplied reveal curious differences between the printed posts and those online. Why, for instance, does a graph that links rising bear attacks to rising temperature in the book, plot bear attacks against human population on the web?

The entries highlight the great variety of styles that can thrive in the blogosphere. Most of the pieces are a little chattier than the usual book or magazine article, but those chosen are formal enough not to grate on the printed page. Occasionally, the prose is loftier than a typical popular science book. Some even veer too much towards the tone of a research article leaving terms like suprachiasmatic nucleus or a zygomaticomaxillary suture unexplained.

The book works well enough as a standalone anthology of science writing, but I share the editor's hope that it will prompt eager print readers hitherto unfamiliar with the vibrant young medium that is science blogging to have a look, and maybe even have a go. Nominations for next year's anthology are already being sought (http://openlab.wufoo.com/forms/ submission-form/). It will be interesting to see how this project develops over coming years as the blogosphere itself evolves.

Paul Stevenson is a nuclear physicist at the University of Surrey, Guildford, GU2 7XH, UK. 